\title{
AGE RELATED CHANGES IN HUMAN PROSTATE GLAND: A MICROSCOPIC STUDY
}

\author{
Lathi Kumari Kalyanikutty Amma1, Usha Devi Keezhathil Bhargavi², Ammu Sreeparvathi', Nandagopan $S^{4}$
}

${ }^{1}$ Additional Professor, Department of Anatomy, Government T D Medical College, Alappuzha, Kerala.

${ }^{2}$ Additional Professor, Department of Anatomy, Government Medical College, Trivandrum, Kerala.

${ }^{3}$ ENT Surgeon, SUT Hospital, Trivandrum, Kerala.

${ }^{4}$ Oral and Maxillofacial Surgeon, SMIDS, Kanyakumari, Tamilnadu.

\section{ABSTRACT}

\section{BACKGROUND AND AIM}

Prostate is considered to be a potentially active organ of the male reproductive tract. With increase in age, prostate undergoes hyperplasia, which is of clinical relevance. This study is aimed at looking into the microscopic changes of prostate, as age passes by.

\section{SETTINGS AND DESIGN}

This study was done in Kottayam and Alappuzha Government Medical Colleges in Kerala. My study was an observational study done in Post-mortem specimens.

\section{MATERIALS AND METHODS}

The study included 65 human prostates, collected from the Forensic and Pathology Departments of Government Medical Colleges, Kottayam and Alappuzha. The collected specimen were categorised to different decades according to the age and a study of the pattern of the histological changes in different decades were done. Using light microscopy, the sequence of changes occurring in the glandular and stromal elements of prostate with respect to age were assessed.

\section{RESULTS AND CONCLUSIONS}

Foetal prostate consists of rudimentary duct system embedded in fibromuscular stroma. Follicles begin to appear in the second decade of life. After 45 years, gland undergoes hyperplasia. Atrophic changes do occur after 60 years. This study also provides objective evidence to demonstrate that the prostate does not have a true capsule. Observations of the undertaken study indicates that age-wise changes do occur in the prostate gland and has a definite pattern of sequential changes with relation to the different periods of life.

\section{KEYWORDS}

Prostate, Capsule, Hyperplasia, Corpora amylacea, Stroma.

HOW TO CITE THIS ARTICLE: Amma LKK, Bhargavi UDK, Sreeparvathi A, et al. Age related changes in human prostate gland: A microscopic study. J. Evolution Med. Dent. Sci. 2016;5(75):5558-5563, DOI: 10.14260/jemds/2016/1256

\section{INTRODUCTION}

Prostate is of great clinical importance in males because of its affinity for inflammatory, congestive, hyperplastic and neoplastic disturbances. The frequency of the prostatic disorders has been on the increase. Most men over the age of 40 years are likely to develop benign prostatic hyperplasia or carcinoma which are related to age. The human prostate is a composite organ made up of several glandular and nonglandular elements, tightly packed together within a common capsule. Each of these elements have a characteristic and unique predisposition to disease. Therefore, study of the microanatomy of prostate would be profitable.

\section{MATERIALS AND METHODS}

The study included 65 specimens of human prostate collected within 6 hours after death. Specimens included 59 adult

Financial or Other, Competing Interest: None.

Submission 14-08-2016, Peer Review 06-09-2016,

Acceptance 12-09-2016, Published 17-09-2016.

Corresponding Author:

Dr. Lathi Kumari Kalyanikutty Amma

Sankaram, Silver Hills,

Poonthi Road, Anayara P.O,

Trivandrum-695029,

Kerala.

E-mail: lathi.sk@gmail.com

DOI: $10.14260 /$ jemds/2016/1256 prostates and 6 foetal prostates. Specimens were grouped according to age from foetal period to $8^{\text {th }}$ decade.

After removing the prostate from the lesser pelvis, it is immediately transferred to the fixative solution- $10 \%$ formalin. The fixed specimens were subjected to the process of paraffinisation. The tissue bits were placed in tissue capsules and the same were processed by standard methods. That is, at first they were subjected to dehydration by serial passage through ascending grades of alcohol. The dehydrated specimens were cleared in xylol and then embedded in paraffin wax using 'L' blocks. The blocks were cut serially at 5 micron thickness in a microtome and mounted on 5 slides with 4 sections on each slide. The sections after incubation were subjected to the staining reaction with routine haematoxylineosin method, and with special stains, Masson's Trichrome and Verhoeff's method.

\section{OBSERVATIONS}

Observations were made on the basis of microscopic study. Substance of the prostate is made up of a large number of individual glands that are embedded in a stroma that is a mixture of smooth muscle and fibrous connective tissue. In a sexually mature male, the epithelium of secretary unit and ducts is of tall columnar type. Beneath this columnar type, flattened or rounded basal cells were distributed irregularly. Epithelium and subjacent connective tissue form folds that project into the lumen giving a pseudopapillary pattern 
(Fig: 1). Spherical bodies of prostatic concretions or corpora amylacea are seen in the secretary unit of some adult males (Fig: 2).

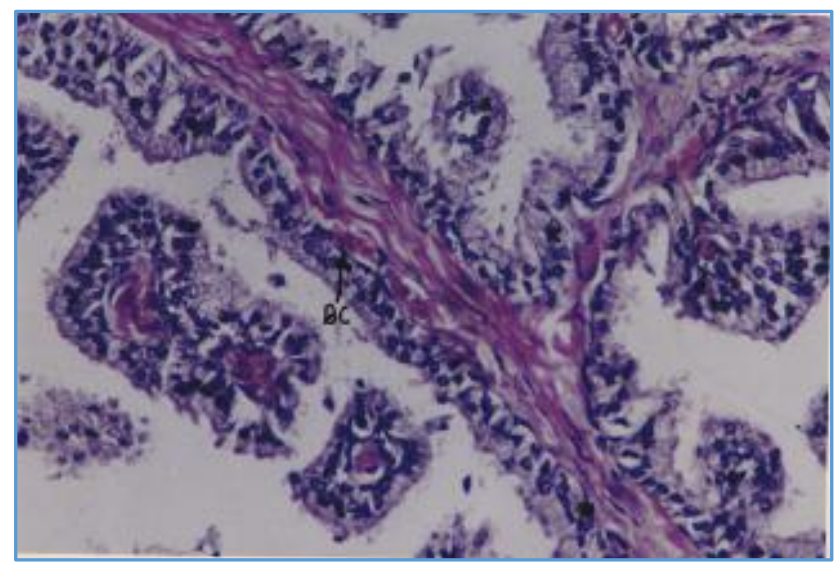

Fig. 1: 28-year-old prostate. Secretory unit consists of tall columnar luminal cells and flattened basal cells (BC) $\times 200 \mathrm{H \& E}$

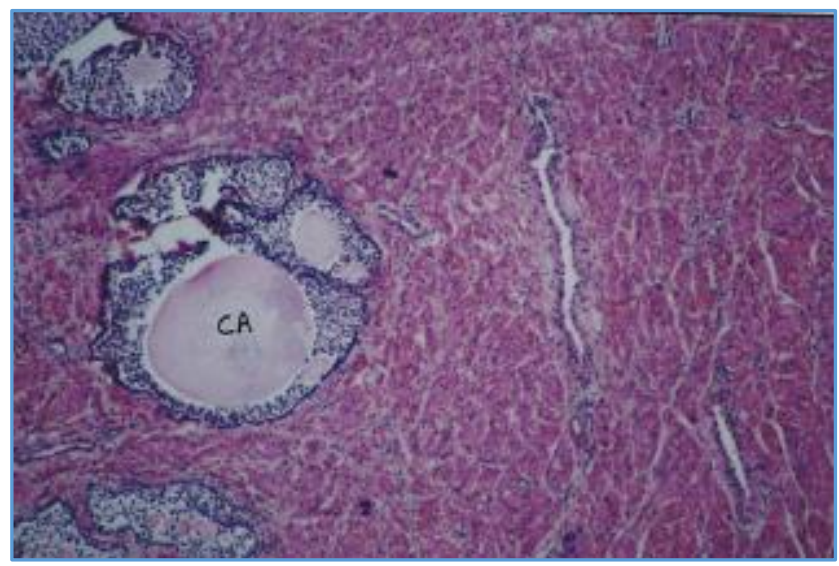

Fig. 2: 35-year-old prostate. Spherical body of corpora amylacea (CA) nested within the secretory unit $x$ $50 \mathrm{H \& E}$

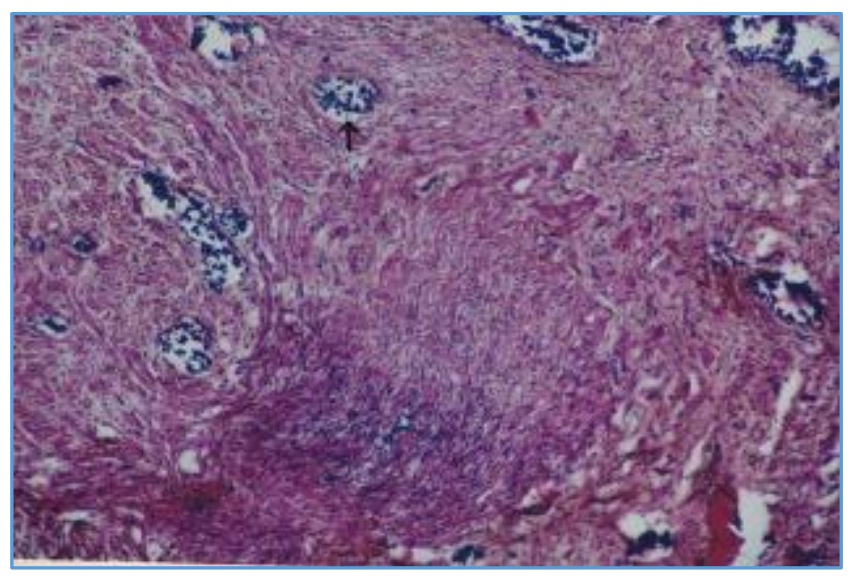

Fig. 3: Foetal prostate rudimentary duct system ( $)$ embedded in fibromuscular stroma $\times 50 \mathrm{H \& E}$

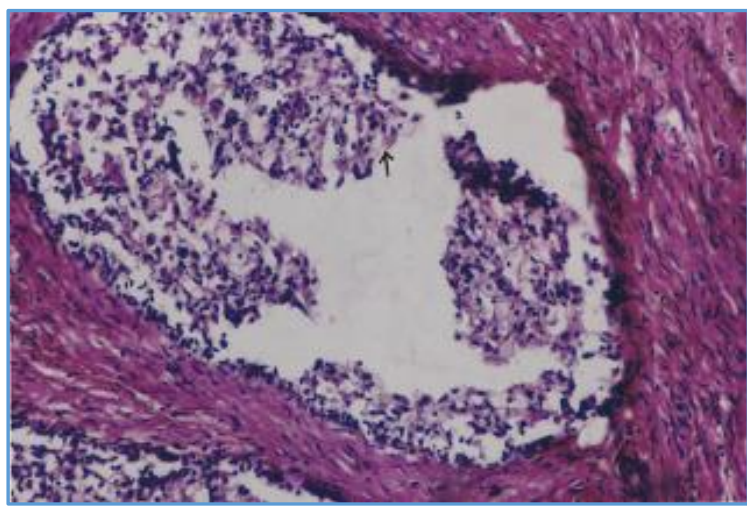

Fig. 4: Foetal prostate. Squamous metaplasia of ductal epithelium (†) X $200 \mathrm{H \& E}$

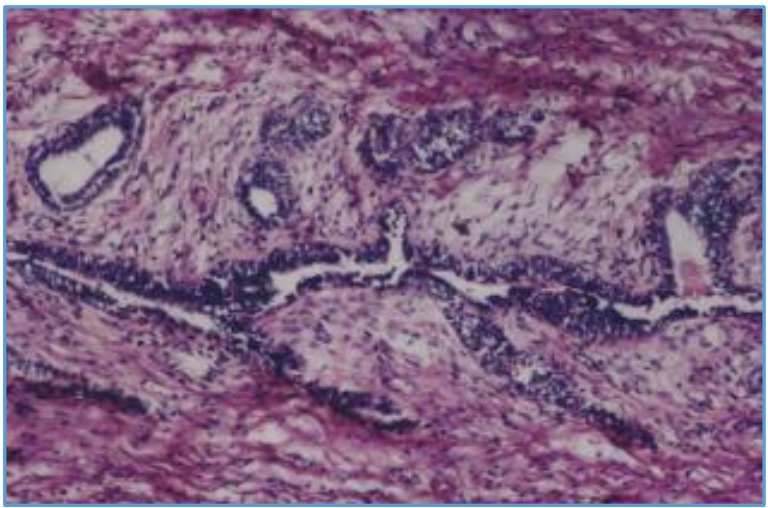

Fig. 5: 11-year-old prostate showing follicles $x 100 \mathrm{H} \& \mathrm{E}$

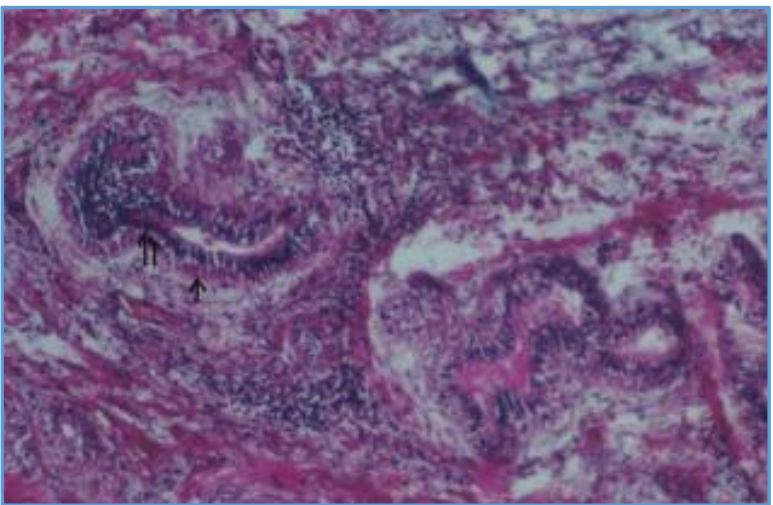

Fig. 6: 12-year-old prostate. Bilaminar ductal epithelium with basal cuboidal ( $\uparrow$ and luminal columnar cells $(\uparrow \uparrow) \times 100$ Masson's Trichrome

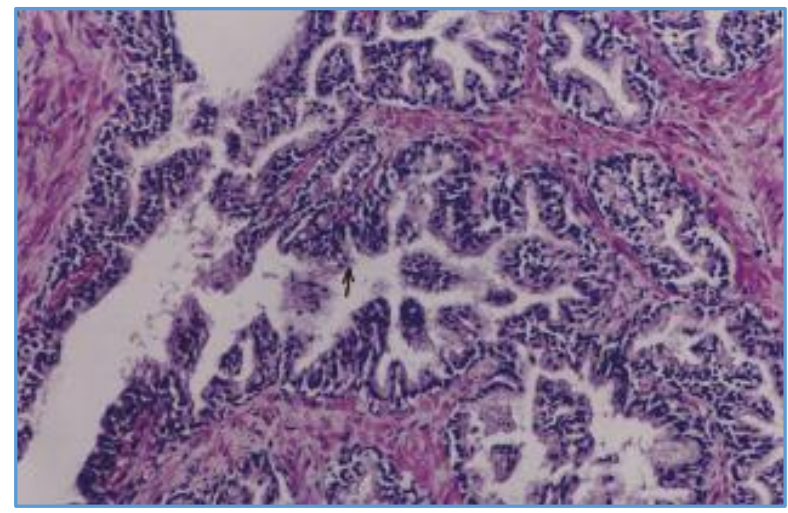

Fig. 7: 25-year-old prostate. Glandular epithelium increased by irregular infoldings. Epithelium \& subjacent connective tissue form folds giving a pseudopapillary pattern (†) x 100 $H \& E$ 


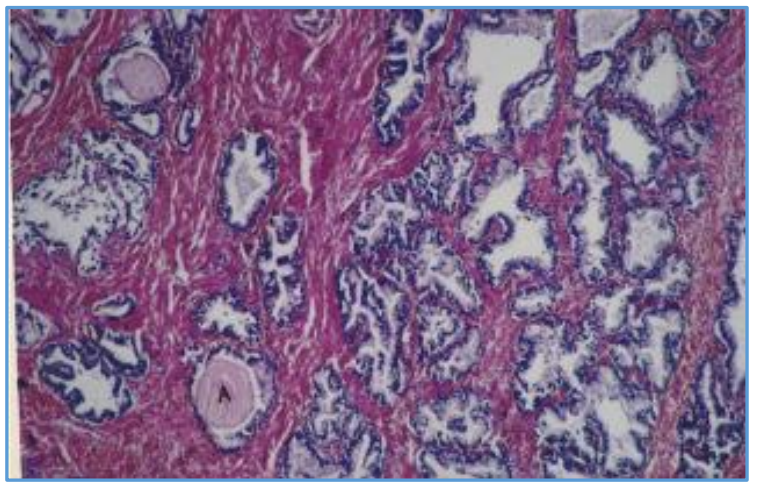

Fig. 8: 23-year-old prostate showing homogenously pink spherical body corpora amylacea (A) within the acinus. $X 50 \mathrm{H} \& \mathrm{E}$

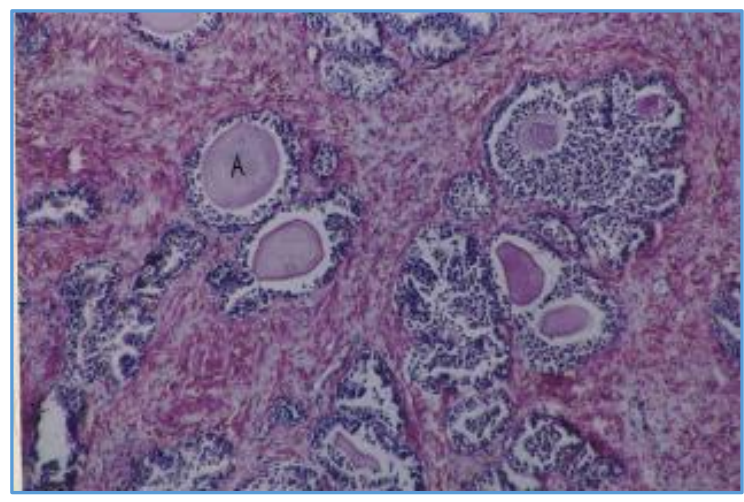

Fig. 9: 38-year-old prostate showing numerous corpora amylacea (A) x $50 \mathrm{H} \& \mathrm{E}$

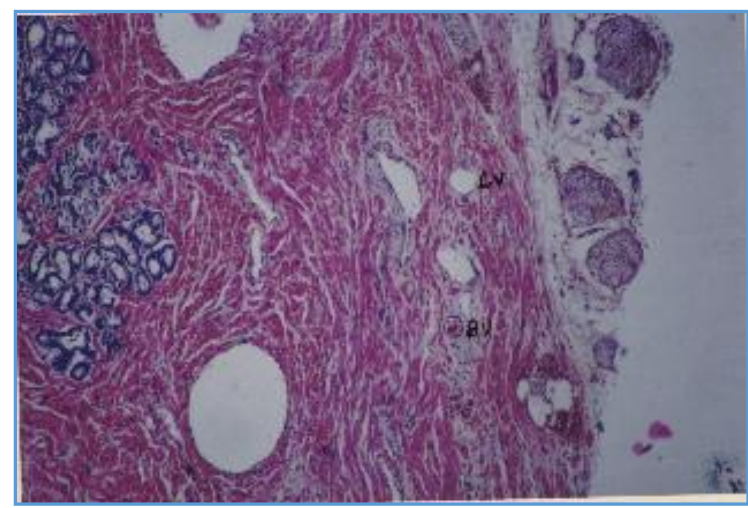

Fig. 10: Prostatic capsule. Layer of lightly stained collagen between darkly stained smooth muscle bands. Lymphatic and blood vessels (LV) (BV) are seen $x 50 \mathrm{H} \& \mathrm{E}$

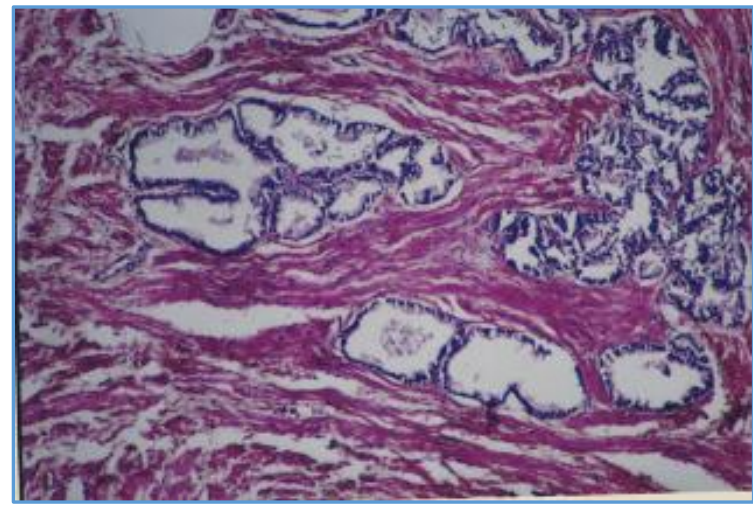

Fig. 11: 43-year-old prostate. Infoldings disappear. Outline regular. Epithelium changed to low columnar. X $50 \mathrm{H \& E}$

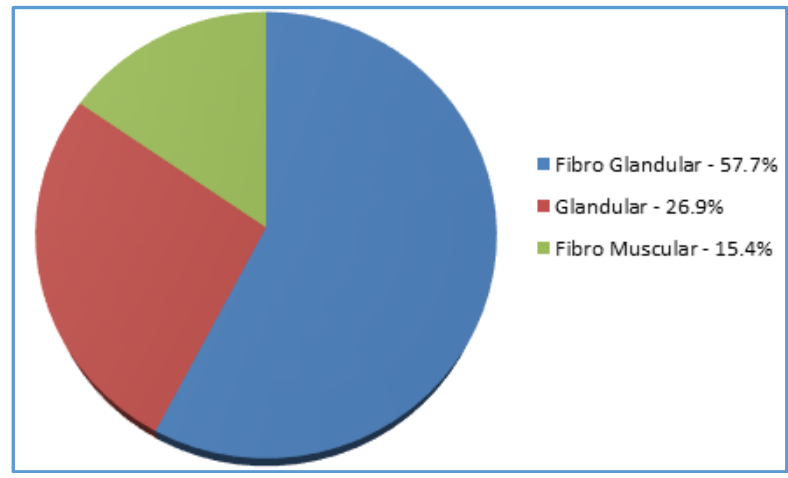

Fig .12: Proportion of various types of Hyperplasia

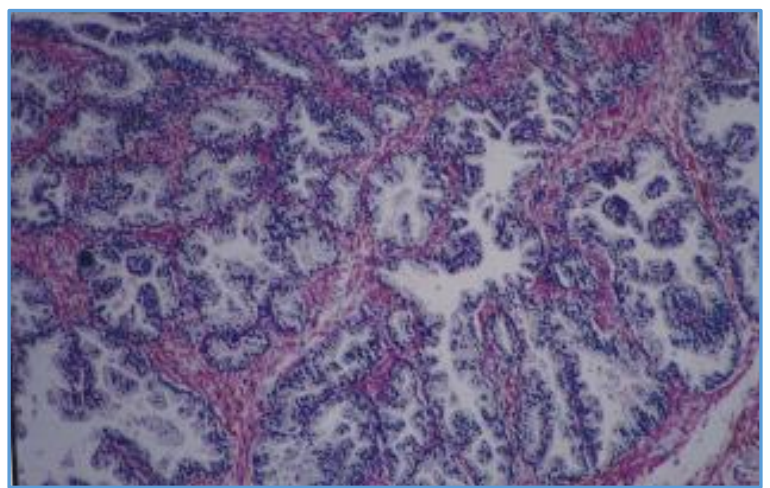

Fig. 13: 55-year-old prostate showing glandular hyperplasia. Glands are tortuous. Stroma less. X $50 \mathrm{H \& E}$

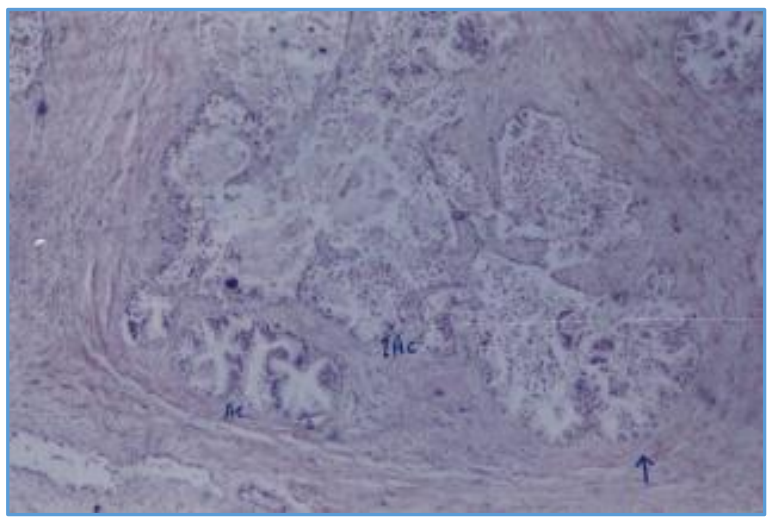

Fig. 14: 57-year-old prostate. Fibroglandular hyperplasia 'Active' (Ac)- tall columnar epithelial cells \& inactive (IAc) cuboidal cells line the hyperplastic glands. False capsule around adenomatous nodule (T) × $50 \mathrm{H} \& \mathrm{E}$

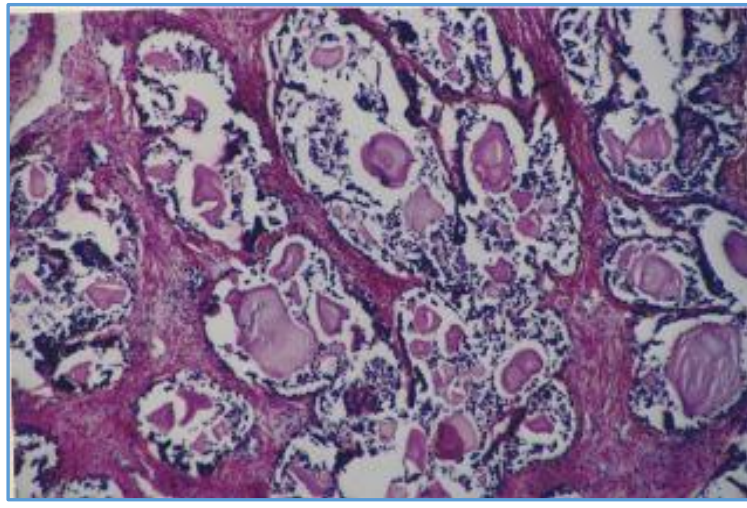

Fig. 15: 64-year-old prostate. Prostatic atrophy. Marked distension of acini, sloughing of epithelium $x 50 \mathrm{H \& E}$ 


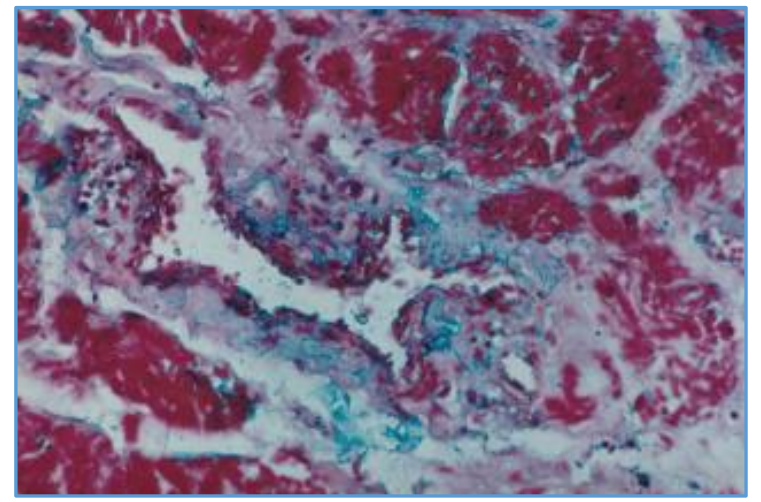

Fig. 16: 67-year-old prostate. Periglandular collagen rings stained blue. X200 Masson's Trichrome

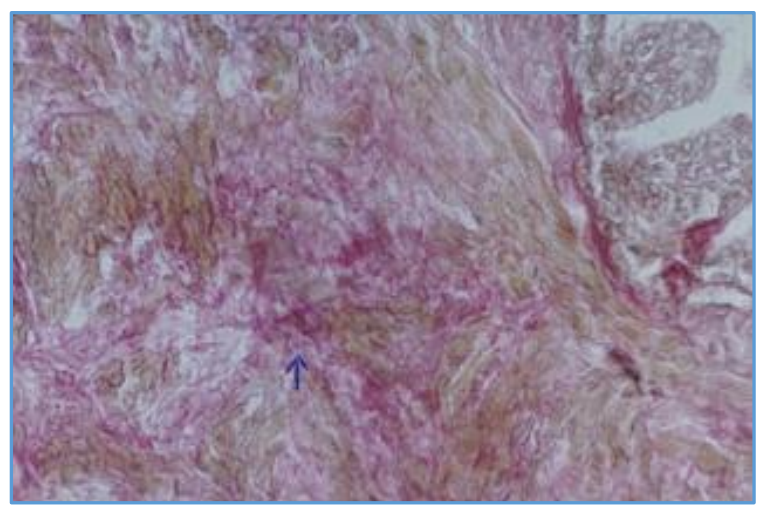

Fig. 17: 62-year-old prostate showing collagen fibres stained pink (†). Elastic fibres lacking X 100 Verhoeff's method

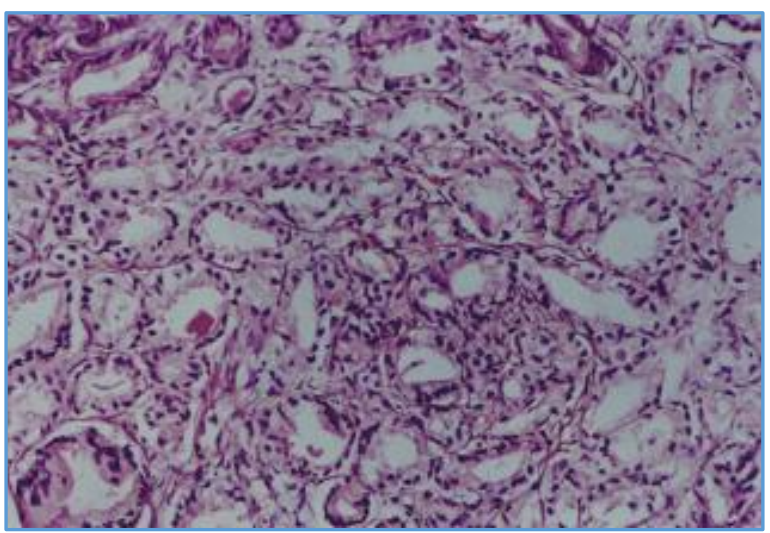

Fig. 18: 65-year-old prostate. Adenocarcinoma. Acini grouped together. Architecture abnormal stroma lacking X $50 \mathrm{H} \& \mathrm{E}$

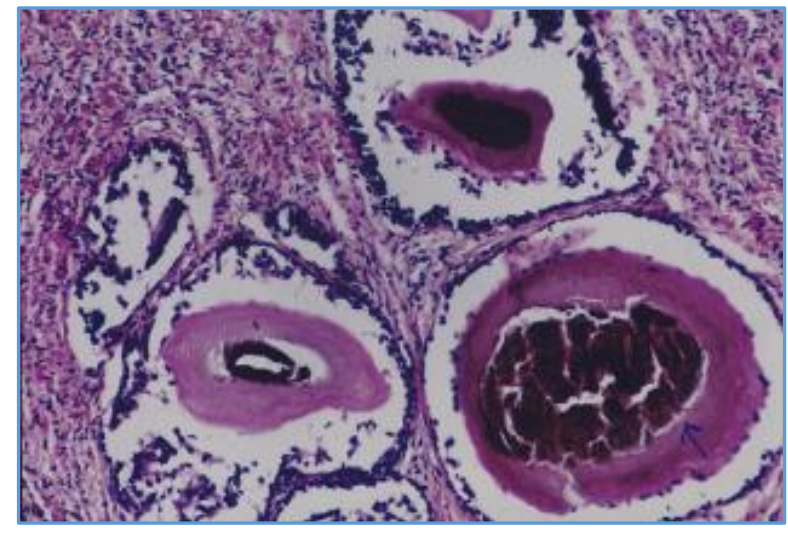

Fig. 19: 73-year-old prostate showing prostatic calculi († X200 H\&E

\section{Changes During Different Decades of Growth}

Foetal period- shows rudimentary duct system embedded in fibromuscular stroma. Stroma amount for a large part of the bulk of the gland. Primordial acini appear as cluster of cells in fibromuscular stroma (Fig: 3). First decade (1-10 years) shows hyperplasia of ductal epithelium. Fibromuscular stroma is abundant. Certain acini shows squamous metaplasia in the beginning of the decade (Fig: 4). Second decade (11-20 years) - follicles begin to appear. There is elaboration of ducts and acini and reduction in the amount of stroma. Epithelium shows hyperplasia giving a pseudostratified appearance. Follicles have no folding (Fig: 5). 12-year-old specimen stained with Masson's Trichrome shows bilaminar ductal epithelium with basal cuboidal and luminal columnar cells with darkly stained nuclei (Fig: 6). Third decade (21-30 years) - Elaboration of follicles present. Glandular epithelium is increased by irregular infolding into the lumen giving a pseudopapillary pattern. Acini are lined by tall columnar cells with flattened cells beneath it (Fig:7). 23-year-old prostate stained with H\&E showed homogenously pink spherical bodies of corpora amylacea nested within the lumen (Fig:8). Fourth decade (3140 years) - Acini show infoldings. There is condensation of stroma. Corpora amylacea are common (Fig: 9). Capsule consists of layers of lightly stained collagen fibres between darkly stained smooth muscle bands. Fibrous tissue of capsule merges with that of the gland and there is no distinct boundary between the capsule and the gland proper. Lymphatics and blood vessels are seen (Fig: 10). Fifth decade (41-50 years)Infoldings of epithelium gradually disappear.

Outline of follicles becomes more regular. Epithelium is changed to low columnar or cuboidal (Fig: 11). Sixth decade (51-60 years) -Most of the specimen showed hyperplasia. Most striking microscopic feature of prostatic hyperplasia is; the variation in the appearance of the structure in different parts of the prostate in contrast to the uniformity observed in the normal prostate. $26.9 \%$ of cases showed glandular hyperplasia that is the glandular component is greatly increased (Fig: 12). The acini are enlarged and a marked tendency to intra-acinar proliferation is seen (Fig: 13). 15.4\% shows fibromuscular or stromal hyperplasia and the epithelial proliferation is minimal. Elastic fibres take up very little eosin whereas smooth muscle fibres are darkly stained. $57.7 \%$ of specimen shows mixed histological pattern. There is hyperplasia of varying proportion of the glandular and the stromal tissues. Epithelial cells lining the hyperplastic glands are of two types, 'active' and 'inactive'. Active cells seen in the normal mature glands are tall columnar cells with poorly defined boundaries, with basal nuclei often forming a double layer, papillae are numerous. Inactive cells are low columnar or cuboidal type with well-defined cell walls and single layered basal nuclei, papillae are few. Loose fibromuscular stroma intervene between acini (Fig: 14 ).

Seventh decade (61-70 years) - Atrophic changes are mainly noticed. Ducts and acini are lined with flattened epithelium which lack true papillae. Lumen contains corpora amylacea with concentric layers that stains with different intensities which is evident when calcification begins. Ballooning of acinus with sloughing of epithelia or cystic acinus are seen (Fig: 15). Sections stained with Masson's Trichrome shows periglandular collagenous ring, which is a sign of atrophy or periglandular fibrosis (Fig: 16). 73-year-old prostate stained with Verhoeff's method shows less elastic and 
more collagen fibres (Fig: 17). Concurrent malignancy is also observed with epithelial cells of uniform size with large nuclei. Acini are grouped together, small and irregular in shape, architecture is abnormal, stroma is lacking (Fig: 18).

\section{DISCUSSION}

The purpose of the undertaken study was to demonstrate the histological changes in the human prostate during successive physiological stages of growth. The observations recorded demonstrate that changes do occur in the structure of prostate in various decades of life.

According to Swyer (1944).,1 human prostate undergoes several growth phases. Just after birth, the gland consists of few ducts embedded in a greater mass of stromal elements. The epithelial cells of the ducts multiply and change into squamous type and this change is possibly brought about by the presence of maternal oestrogen circulating in foetal blood. Andrews (1951). ${ }^{2}$ also found squamous metaplasia as a result of maternal oestrogen stimulation. The above statements regarding the histological appearance of foetal prostate can be correlated with the findings of the present study. According to Swyer, elaboration of duct system starts at 9 years. But in the present study, elaboration of duct system and appearance of follicle starts at the beginning of second decade. During early adulthood, the glandular epithelium is increased by the infolding of the epithelium. These changes are in accordance with the present findings. Hyperplasia of ductal epithelium giving a pseudostratified pattern agrees with the view of Aumuller $(2012)^{3}$. In the present study, follicles begin to appear in the second decade and elaboration of acini are noticed after 15 years which supports the view of Shiraishi et al (2002). 4

Present study showed adult prostate consists of fibromuscular tissue which constitute one third of the whole mass and the glandular epithelium is simple or pseudostratified columnar. Epithelium gives a pseudopapillary pattern and these findings are in accordance with the normal histology of adult prostate described by Wilfred, Robbins and Fawcett (1994). ${ }^{5}$ and Ansell ID (1992). ${ }^{6}$ According to Swyer 1944.1 after the third decade, the infoldings tend to disappear, so that the outlines of follicles are more regular, whereas in the present study, infoldings gradually disappear during the beginning of $5^{\text {th }}$ decade. Anderson (1985). ${ }^{7}$ reported that hyperplasia seldom occurs before the age of 50 years, but the incidence increases with age. This is contradictory to the present finding that the atrophic changes are mainly observed during $7^{\text {th }}$ decade and most of the specimens during $6^{\text {th }}$ decade show hyperplasia. $F$ K Mostofi $(1970)^{8}$ suggested that the hyperplasia occur after the age of 40 years reaches its maximum intensity at about 60 years and continues to be present in sufficient amount to cause changes during remainder of life. These agree with the findings of present study.

According to Ansell (1992) ${ }^{6}$, hyperplasia affects fibrous tissue, glandular tissue and smooth muscle. The present study demonstrated three types of hyperplasia - glandular, fibromuscular and mixed. It was observed that most of the nodules are mixed in type. These findings are in agreement with the observations of Dorflinger $T$ (1988). ${ }^{9}$ Present observations regarding the epithelial cells lining the hyperplastic glands reinforce the findings described by Moore (1943). ${ }^{10}$ He designated the cells as active and inactive. The undertaken study, showed atrophic changes after 60 years. There is flattening of epithelium, true papillae are not present and periglandular collagen rings are seen. Most of the acini are nested with corpora amylacea. There is a tendency for corpora amylacea to increase in number. This may become a site of calcium deposition and when calcified they are designated as calculi (Fig:19). Findings of this work regarding atrophy can be correlated with McNeal (1988).11 In the present study, it was noted that 23 years aged specimen showed corpora amylacea and there was no evidence of inflammation or hyperplasia. For this reason, there is difficulty in defining the appearance of corpora amylacea as an indication of involution.

Sattar AA (1995). ${ }^{12}$ and Ayala et al (1989). ${ }^{13}$ studied about the prostate capsule and concluded that prostate does not have a true capsule. The present study also demonstrates that the prostate does not have a true capsule but a fibromuscular band which consists of smooth muscle and connective tissue; there is marked variability in the relative amounts of muscle and fibrous tissue from area to area. So the capsule cannot be regarded as a well-defined anatomic structure with constant features. Concurrent benign prostatic hyperplasia occurs in almost all men developing malignancy according to Rifkin M D, (1991). ${ }^{14}$ In the present study, two specimens showed histological changes of adenocarcinoma along with hyperplasia.

Overall, the present study demonstrated significant histological changes in the prostate as age progresses. Moreover, in my study a 23-year-old specimen had shown corpora amylacea with no evidence of inflammation or hyperplasia indicating that it cannot be considered as a sign of involution- and this requires further confirmation by research.

\section{REFERENCES}

1. Swyer GI. Post-natal growth changes in the human prostate. Journal of Anatomy 1944;78(Pt 4):130-45.

2. Andrews GS. The histology of the human foetal and prepubertal prostates. Journal of Anatomy 1951;85(1): 44-54.

3. Aumüller G. Prostate gland and seminal vesicles. Springer Science \& Business Media 2012:p 380.

4. Shiraishi T, Kato H, Komada S, et al. Tenascin expression and postnatal development of the human prostate. International Journal of Developmental Biology 1994;38(2):391-5.

5. Fawcett DW, Bloom W, Raviola E, et al. Bloom and Fawcett, a text book of histology. $12^{\text {th }}$ edn. New York, London: Chapman \& Hall 1994:804-6.

6. Ansell ID. Oxford text book of pathology. Vol. 2a. 1992:1535-9.

7. Anderson WAD, Kissane JM. Anderson's pathology Vol. 1. $8^{\text {th }}$ edn. St. Louis: The CV Mosby Company 1985:817-20.

8. Mostofi FK. Benign hyperplasia of the prostate gland. In: Campbell MF, Harrison JH. eds. Urology. Vol II. $3^{\text {rd }}$ edn. Philadelphia, London and Toronto: WB Saunders 1970:1067-75.

9. Dorflinger T, England DM, Madsen PO, et al. Urodynamic and histological correlates of benign prostatic hyperplasia. Journal of Urology 1988;140(6):1487-90.

10. Moore RA. Benign hypertrophy of the prostate. Journal of Urology 1943;50:680.

11. McNeal JE. Normal histology of the prostate. American Journal of Surgical Pathology 1988;12(8):619-33. 
12. Sattar AA, Noël JC, Vanderhaeghen JJ, et al. Prostate capsule: computerized morphometric analysis of its components. Urology 1995;46(2):178-81.

13. Ayala AG, Ro JY, Babaian R, et al. The prostatic capsule: does it exist? Its importance in the staging and treatment of prostatic carcinoma. The American Journal of Surgical Pathology 1989;13(1):21-7.
14. Rifkin MD. Ultrasound of the prostate-applications and indications. Schweiz Med Wochenschr 1991;121(9): 282-91. 